\title{
Estereotipos de género sobre Camila Vallejo en un diario sensacionalista chileno: el caso de Las Últimas Noticias
}

\author{
Pamela Soledad Romero Lizama ${ }^{1}$ (iD 0000-0003-0191-128X \\ 'Universidad Católica del Norte, Antofagasta, Región de Antofagasta, Chile. 1270709
}

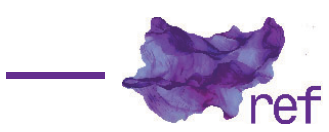

Resumen: Esta investigación abordó de manera crítica el discurso del diario chileno sensacionalista Las Últimas Noticias sobre la líder estudiantil Camila Vallejo durante los años 2010 y 2011. Este periodo fue elegido debido a la importancia nacional e internacional del movimiento estudiantil chileno y corresponde al tiempo en que Camila Vallejo ejerció como presidenta de la Federación de Estudiantes de la Universidad de Chile. Por medio del análisis crítico se comprueba que Camila Vallejo fue discriminada por ser mujer, por ser joven y también por su ideología de izquierda. Lo anterior reafirma que los medios de comunicación tradicionales y conservadores en Chile aún siguen estigmatizando a las mujeres y transmitiendo estereotipos de género.

Palabras clave: Camila Vallejo; Chile; movimiento estudiantil; medios de comunicación; análisis crítico del discurso. Estereótipos de gênero sobre Camila Vallejo em um tabloide chileno: o caso de Las Últimas
Noticias
Resumo: Esta pesquisa abordou criticamente o discurso do tabloide chileno Las Últimas Noticias
sobre a líder estudantil Camila Vallejo durante 2010 e 2011 . Esse período foi escolhido devido à
importância nacional e internacional do movimento estudantil chileno e corresponde à época em
que Camila Vallejo era presidente da Federação de Estudantes da Universidade do Chile. Através da
análise crítica, fica comprovado que Camila Vallejo foi discriminada por ser mulher, por ser jovem
e também por sua ideologia de esquerda. Isso reafirma que a mídia tradicional e conservadora no
Chile ainda estigmatiza as mulheres e transmite estereótipos de gênero.

Palavras-chave: Camila Vallejo; Chile; movimento estudantil; meios de comunicação; análise crítica do discurso.

Gender Stereotypes about Camila Vallejo in a Chilean Sensationalist Newspaper: the Case of Las Últimas Noticias

Abstract: This research critically studied the speech of the Chilean sensationalist newspaper Las Últimas Noticias about the student leader Camila Vallejo during 2010 and 2011. This period was chosen due to the national and international importance of the Chilean student movement and corresponds to the time Camila Vallejo was president of the Federation of Students of the University of Chile. The critical analysis reveals that Camila Vallejo was discriminated against for being a woman, for being young and for her left-wing ideology. This reaffirms that traditional and conservative media in Chile still stigmatizes women and transmits gender stereotypes.

Keywords: Camila Vallejo; Chile; Student movement; Media; Critical discourse analysis.

\section{Introducción}

El artículo que aquí se presenta reflexiona de forma teórica y práctica sobre la manera en la que los medios de comunicación reproducen y propagan estereotipos de mujer de acuerdo con la sociedad patriarcal. Se abordó críticamente el discurso del diario chileno sensacionalista 
Las Últimas Noticias sobre la líder estudiantil Camila Vallejo durante los años 2010 y 2011 . Este periodo fue elegido debido a la importancia nacional e internacional del movimiento estudiantil chileno y corresponde al tiempo en el que Camila Vallejo ejerció como presidenta de la Federación de Estudiantes de la Universidad de Chile (Fech).

Se conjuga en este caso una situación atractiva para estudiar cómo un diario sensacionalista con tendencias ideológicas de derecha y enfocado principalmente en lectores de clase media y clase baja se interesa en la política y en los movimientos sociales del país.

Para ello, se utilizó el Análisis Crítico del Discurso como base para la interpretación de las informaciones, encontrando así los principales estereotipos de género a los que se asoció a Camila Vallejo, poniendo de manifiesto el sexismo y la discriminación presentes en el diario Las últimas Noticias.

\section{La sociedad patriarcal}

Vivimos en una sociedad dominada por los hombres. Esto es lo que se ha denominado el patriarcado. Históricamente, las mujeres se han visto alejadas de los puestos de poder y relegadas a lo privado, y han sido los hombres quienes han controlado el curso de los acontecimientos, dominando los ámbitos materiales y discursivos de la vida.

Amelia Valcárcel entiende el patriarcado como una política sexual ejercida por el colectivo de los hombres, a partir de la definición de la posición secundaria de las mujeres (VALCÁRCEL, 2013). El patriarcado es un sistema de dominación social que se sostiene sobre una desvalorización de la mujer para perpetuar el poder de los hombres. Podemos decir que es una especie de acuerdo entre los hombres, mitad de la especie humana que se ve favorecida por el orden de las cosas. Pero la sociedad patriarcal no ha existido siempre, y se puede hacer un recorrido histórico para encontrar y conocer las raíces de su instauración.

En realidad, en muchas culturas ancestrales existían sociedades matrilineales y matrilocales, en las que la mujer era la líder indiscutida, en consideración a su capacidad de dar vida. Su figura se asociaba a la fertilidad y fecundidad. Cuando nuestros antepasados Homo habilis habitaban la tierra, las relaciones entre hombres y mujeres tendían hacia el igualitarismo. En las sociedades recolectoras y horticultoras la mujer era respetada, debido a que ella predominaba en la recaudación y producción de los alimentos. En estas sociedades matriarcales, la mujer era la propietaria de la tierra y había una mayor libertad sexual para ella. Pero todo esto comenzó a cambiar a partir de la división del trabajo, en la que el hombre comenzó a incorporarse a la agricultura, generando un decaimiento de las sociedades matrilineales y matrilocales (Filippo Giuseppe DI BENNARDO, 2009).

Las mujeres empezaron a ser vistas como productoras de fuerza de trabajo y fueron divididas entre sí, apartadas de otras mujeres, perdiendo la protección y transformándose en herramientas reproductivas y en propiedad de los hombres. La mujer se vio relegada a lo privado, a las tareas del hogar y al cuidado de la familia, en tanto que el hombre se transformó en protagonista del mundo público.

Victoria Sau sostiene que, a través del patriarcado, la mujer comenzó a vivir atrapada por el hombre, dependiendo completamente de él, como si se tratara de un embarazo. Y que el hombre no se dio cuenta de esta condición hasta que las mujeres comenzaron a luchar por sus derechos: "A partir del patriarcalismo la mujer vivió en simbiosis con el varón lo mismo que el feto con la madre. Se alimentó de lo que él le daba y participó del mundo no por vía directa, sino a través del hombre" (SAU, 1975, p. 6).

El hombre entendió que solamente podía asegurarse la paternidad de los hijos en la medida que ejerciera poder sobre su mujer, puesto que le resultaba más difícil controlar a todos los demás hombres. Los hijos serían una proyección de sí mismo y, de esta manera, el hombre alcanzaría la inmortalidad: "El poder y la propiedad pueden ser transmitidos a los hijos y ser de este modo conservados desde la tumba" (Eva FIGES, 1972, p. 39).

El control se comenzó a ejercer sobre la mujer, tanto física, como mentalmente. Las ventajas del control mental, que conocemos como tabúes o mitos, eran las de relacionarlos a poderes ajenos al control terrenal, y la posibilidad de afectar no solamente a las mujeres, sino a los demás hombres. Esto funcionó y dio origen a la sociedad que conocemos como patriarcal, en la que los sexos y la genitalidad son los que definen nuestra manera de comportarnos y nuestros roles. Al hombre le corresponde el rol activo en todos los sentidos, en cambio, la mujer es asociada a la pasividad. La inferioridad de la mujer, con ayuda de instituciones como la religión, el matrimonio, las ciencias, el sistema educacional e incluso los medios de comunicación, se ha convertido en ley.

\section{Estereotipos de mujer}

Hay diferentes roles a los que, en la sociedad patriarcal, han sido destinadas las mujeres. Por tanto, hay un cierto tipo de características, descripciones, cualidades y habilidades con las 
que se representa a la mujer según su sexo. Eso es lo que vamos a entender por estereotipo: una definición de un conjunto, socialmente aceptada, basada en ciertos patrones preestablecidos. Estas generalizaciones "Pertenecen al imaginario colectivo y se nos presentan como la pura realidad objetiva e incuestionable" (Juan Carlos SUÁREZ, 2007, p. 6).

Según Estrella Israel, los estereotipos son más falsos que verdaderos y no están basados en una experiencia directa. Para la autora, "Ios estereotipos constituyen un modo establecido de reducir la riqueza de la realidad a unos modelos muy simples" (ISRAEL, 2006, p. 41). Por ejemplo, según la tradición de la religión cristiana, la mujer se define en correspondencia a su relación con su propia sexualidad (DI BENNARDO, 2009). Es así como encontramos la figura de: a) la virgen (ausencia de sexualidad); b) la esposa y madre (sexualidad con el marido); y c) a la prostituta (sexualidad con muchos hombres). Estas tres figuras canónicas siguen dominando la sociedad occidental hasta el día de hoy. Y no solamente las relaciones de las mujeres con los hombres, sino también las relaciones de las mujeres con otras mujeres y consigo mismas.

En la sociedad patriarcal, las mujeres no tienen derecho a decidir sus imágenes. Están obligadas a moverse dentro de las alternativas que les ofrece el ideal masculino: "A las mujeres se les niega el derecho de crear sus propias imágenes de feminidad, y se ven, en cambio, obligadas a conformarse con los modelos machistas que se les imponen" (Toril MOI, 1999, p. 68).

Estos estereotipos marcan tanto a mujeres como a hombres desde antes de nacer $e$ imponen una superioridad neta del hombre y, gracias a la denostación y discriminación hacia las mujeres, constituyen las bases que sostienen el sistema patriarcal. Por medio de estos modelos mentales, los hombres han impuesto control y disciplinamiento sobre las mujeres durante miles de años, haciéndonos creer que nacemos naturalmente inferiores. Moi (1999) sostiene que la opresión de los hombres ha conseguido que las mujeres lleguen a aceptar como habituales unos ciertos modelos de lo que debe ser la mujer, y quienes no aceptan estos modelos son consideradas como no femeninas. Es aquí donde el amor maternal parece ser el eje central de lo que constituye el estereotipo de femineidad. La ternura, la dedicación y otras emociones se explican por la capacidad natural de las mujeres de ser madres.

Por otro lado, también se puede identificar el estereotipo de la mujer malvada, la prostituta. Esta mujer es el "cuerpo para ser mirado, el lugar de la sexualidad y el objeto de deseo" (Víctor SILVA ECHETO, 2003, p. 64). Este estereotipo de mujer es mucho más temido por los hombres, puesto que puede doblegarles el cuerpo y la mente. Figes propone que:

La mujer como fuente de peligro, como depósito de la calamidad exteriorizada, es una imagen que discurre a lo largo de la historia patriarcal. Es bruja, demonio, la mujer escarlata, conspiradora; y su poder sobre las mentes de los hombres normalmente aumenta en proporción inversa a su poder efectivo en el mundo real. (FIGES, 1972, p. 46)

Podemos sostener que estos estereotipos han tenido tanta aceptación social porque se han valido de una triple legitimación para sustentarse: en la ley natural, en la doctrina religiosa y en las teorías científicas, puesto que "El discurso de género fue elaborado por médicos, antropólogos, biólogos, filósofos y científicos sociales" (Mary NASH, 2012, p. 44).

Nash (2012) manifiesta que durante el siglo XIX y parte del XX, el discurso de género puso énfasis en la domesticidad de la mujer bajo estereotipos ideales como el ángel del hogar y la perfecta casada. Este ser angelical, abnegado, asexuado y puro se encargaba de la familia y administraba el hogar, y su integración al mercado laboral podía ser perjudicial, ya que se interponía con sus labores domésticas

El mundo entre las dos guerras mundiales y el cine de Hollywood trajeron otro estereotipo de mujer a la sociedad occidental del siglo XX, que se conoció como la nueva mujer moderna. Este tipo de mujeres se retrataban como "jóvenes solteras llenas de dinamismo y vitalidad que desempeñaban las nuevas actividades modernas femeninas: oficinistas, mecanógrafas, deportistas, ciclistas y conductoras o mujeres de cabaré" (NASH, 2012, p. 64).

En un análisis de las revistas infantiles del universo Disney en los años 60 y 70, Ariel Dorfman y Armand Mattelart hicieron una revisión ideológica de los comics, y allí, en el corazón de la cultura popular que ingresaba a millones de hogares en el mundo y que formó parte de nuestra niñez, también se hacía uso de los estereotipos de género.

A la mujer únicamente se le concede dos alternativas (que no son tales): ser Blanca Nieves o ser la Bruja, la doncella ama de casa o la madrastra perversa. Hay que elegir entre dos tipos de olla: la cazuela hogareña o la poción mágica horrenda. Y siempre cocinan para el hombre, su fin último es atraparlo de una u otra manera. (DORFMAN; MATTERLART, 2002, p. 36)

En palabras de Suárez (2007), cuando hablamos de estereotipos, las personalidades se valoran positivamente para unos (los hombres) y negativamente para otros (las mujeres). El autor hace una lista a modo de ejemplo: los hombres son eficaces, valientes, activos, razonables, juiciosos, inteligentes, tenaces y seguros; en tanto que las mujeres son afectivas, tiernas, débiles, solícitas, intuitivas, temerosas, sumisas y coquetas. Según Suárez (2007), este estereotipo de lo 
femenino y de la mujer actual está marcado fuertemente por la cultura de masas. A través de diferentes investigaciones sobre la imagen contemporánea de la mujer en los medios, el autor puede identificar los siguientes estereotipos: a) La abuelita previsora; b) El ama de casa; c) La triunfadora profesional; d) La mujer objeto; e) La mujer complemento; y f) La adolescente despreocupada.

\section{Sexismo en los medios de comunicación}

Los estereotipos de género se transmiten de generación en generación, perpetuando la imagen de que el hombre es superior a la mujer. En este sentido, el lenguaje y los discursos son un importante móvil para que estos se divulguen, y los medios de comunicación masiva han sido responsables de la perpetuidad y justificación del patriarcado como realidad instituida.

Estas prácticas se pueden denominar sexismo periodístico y se entienden como "el modo como la lengua influye en que se conserve la situación devaluada que vive y que padece la mujer" (Valentina SALAS, 2005, p. 6). Pese al aumento que ha tenido la aparición femenina en los medios, no podemos decir que éste sea positivo en calidad. Por el contrario, y por sobre los esfuerzos por promover el desarrollo de imágenes de mujer que den cuenta de su diversidad y de su participación en la sociedad, es posible observar cómo los mensajes noticiosos las siguen presentando desde los estereotipos. Se continúa exhibiendo a las mujeres como madres, esposas o hijas, subordinadas a los deseos de un varón.

En un estudio de medios argentinos y mexicanos, Paola Bonavitta y Jimena de Garay (2011) demostraron que en las revistas dedicadas a las mujeres se presenta una imagen de mujer como una persona que vive para su pareja: se entregan consejos para llamar la atención de los hombres y para ser como ellos quieren que sean. Las revistas le indican cómo debe vestirse y producir su imagen y además le indican a la mujer que, pase lo que pase, ésta debe sonreír.

Según el estudio del Proyecto de Monitoreo Global de Medios - GMMP (WACC, 2015) , las mujeres únicamente significaron un $24 \%$ de las personas que aparecieron en las noticias de la prensa, televisión o radio. Misma cifra que en el último análisis, que data del año 2010. El monitoreo se desarrolló en más de 100 países, entre ellos, Chile. En nuestro país se analizaron medios escritos tradicionales, canales de televisión y medios digitales. En ellos, las mujeres aparecen solamente en un $32 \%$ de las noticias en medios tradicionales y en un $24 \%$ en medios digitales. Solamente el $3 \%$ de las noticias tienen a una mujer como protagonista. La cifra de presentadores y periodistas en la televisión está relativamente equilibrada $(51 \%$ de mujeres $\mathrm{v} / \mathrm{s}$ $49 \%$ de hombres), lo que no sucede en la prensa, en donde los hombres son los que dominan la escena (68\% v/s $32 \%)$.

Ante el actuar de los medios de comunicación en esta representación de las mujeres, Bonavitta y de Garay (2011) proponen que nos encontramos no solamente frente a un reforzamiento, sino frente a la propia violencia de género, si bien ésta sería de carácter simbólico. En este caso, "el agresor es la sociedad entera, que se sostiene en los pilares del sexismo, el clasismo, el racismo y el heterocentrismo" (BONAVITTA; DE GARAY, 201 1, p. 28).

Entre los esfuerzos que ha habido en Chile por intentar eliminar las prácticas sexistas de los medios de comunicación nacionales, es meritorio destacar la guía Medios no sexistas (2018), publicada por Fabiola Gutiérrez y Mónica Maureira, del Observatorio de Género y Equidad, con el apoyo de la Fundación Friedrich Ebert. En esta guía se presentan una serie de definiciones sobre género y estereotipos de género, además de ejemplos de malas prácticas periodísticas y de recomendaciones para quienes trabajan en los medios de comunicación, principalmente en la cobertura de temas de violencia contra las mujeres.

\section{Camila Vallejo y su rol en el movimiento estudiantil del 2011}

Camila Vallejo Dowling nació en Santiago de Chile el 28 de abril de 1988. Es hija de Reinaldo Vallejo y de Mariela Dowling, ambos militantes del Partido Comunista de Chile desde la década del 70. Durante su infancia, Camila Vallejo vivió en las comunas de Macul y La Florida, en la Región Metropolitana. El año 2006 comenzó a cursar la Licenciatura en Geografía en la Universidad de Chile, casa de estudios a la que había ingresado con solamente 16 años. En el 2013, se tituló como Geógrafa con distinción máxima.

En el año 2007 comenzó a militar en las Juventudes Comunistas. En el 2008 fue consejera de la Federación de Estudiantes de la Universidad de Chile (Fech), y también fue vicepresidenta del Centro de Estudiantes de Geografía, organismo que ayudó a fundar. En noviembre del 2010 fue elegida presidenta de la Fech, representando a la lista E del Colectivo Estudiantes de Izquierda con 2.918 votos. Fue la segunda mujer en ostentar este cargo, después de Marisol Prado, también militante del Partido Comunista, quien fue elegida presidenta de la Fech en 1997. 
Camila Vallejo fue uno de los rostros más visibles del Movimiento Estudiantil del 2011 en Chile, ya que, junto a Giorgio Jackson, presidente de la Federación de Estudiantes de la Pontificia Universidad Católica de Chile, se transformaron en los voceros de la Confederación de Estudiantes de Chile frente a la ciudadanía y a los medios de comunicación.

Muchas de las ideas que entendemos como propias del movimiento estudiantil fueron las que manifestaba Camila Vallejo en cada una de sus intervenciones en las movilizaciones o en los medios de comunicación. Podemos decir que su voz fue la voz de los estudiantes movilizados. Por tanto, es importante destacar su visión en torno a la problemática de la educación en Chile y al movimiento social que se formó en torno a las demandas de los estudiantes.

Según explica Camila Vallejo, el conflicto por la educación en Chile comienza en la medida en que el Estado ha abandonado su rol en la educación y la omite como derecho humano básico, y es desde allí que el empresariado ha asumido un rol preponderante en la educación por casi treinta años, desde la dictadura, enriqueciéndose a costa de los sueños de los jóvenes y sus familias (VALLEJO, 2012). Las universidades, para Vallejo, se han convertido en empresas, medidas bajo parámetros industriales de producción y que no tienen otro norte que el mercado. En ese sentido, el movimiento estudiantil, convocado en la Confederación de Estudiantes de Chile, proponía avanzar en una reforma desde la raíz del sistema educativo chileno, comenzando desde la educación superior.

Respecto al movimiento estudiantil en sí mismo, Vallejo sostiene que no se limitó a la personalidad de los dirigentes, o a un fenómeno generacional, sino que está enmarcado en una historia de luchas sociales en nuestro país:

esto no es algo espontáneo, fruto de una generación a la que se le ocurrió o porque vio en sus líderes una sintonía y le creó mayor convergencia producto de una conducción carismática, sino que surge del aprendizaje de la historia y lo que nosotros hemos visto en nuestra comunidad y de lo que vemos actualmente (...) Esto va a tener una proyección porque la gente ya está cansada, han sido muchos años aguantando, por el temor, por el conformismo, por el individualismo, pero esto no resiste mucho tiempo. La gente despertó; ahora lo importante es que todos asumamos la responsabilidad. (VALLEJO, 2012, p. 35).

Para Vallejo, el movimiento estudiantil fue importante, en la medida en que logró visibilizar no solamente las reivindicaciones de los estudiantes, sino, también, puesto que demostró la crisis del modelo neoliberal que se había implantado en Chile a partir de la dictadura. Y desde ese punto de vista, en el año 2011 la sociedad comenzó a vivir un despertar (Mario GARCÉS, 2012; VALLEJO, 2012) buscando transformaciones estructurales.

Otro aspecto de interés es la manera en que los medios de comunicación presentaron a Camila Vallejo como el principal rostro del movimiento estudiantil. Ella misma reconoce que durante las movilizaciones del 2011 se presentó frente a los medios como una persona más dura de lo que realmente es, para defenderse de la exposición pública. Además, considera que había que darle un rostro al movimiento social por la educación, para traducir la complejidad de toda esa problemática en una imagen simple, y ella estaba a la mano y podía ser interesante para los medios de comunicación (Beatriz SÁNCHEZ, 2014).

Es innegable que, además de su elocuencia, una de las características que más se resaltó mediáticamente fue su apariencia física. Su belleza, acorde a los cánones occidentales, fue la característica que más atrajo, tanto a sus seguidores como a sus detractores. Los medios de comunicación destacaron a Camila Vallejo por su belleza, ya fuese por su armonioso rostro como por su delgada figura, de acuerdo con los patrones sexistas y patriarcales dominantes (Pamela ROMERO, 2013).

Por otro lado, Camila Vallejo logró superar los estereotipos sobre los líderes comunistas de antaño. Su calma y serenidad frente a las preguntas incómodas y a los ataques directos la llevó poco a poco a ir conquistando a la ciudadanía. Es posible sostener que Camila Vallejo nunca perdió la compostura en el debate de ideas, a pesar de que muchas personas la descalificaban, asegurando que su poder estaba relacionado a su belleza (Diamela ELTIT, 2012, p. 196).

Eltit (2012) mantiene que Camila Vallejo es la dirigente estudiantil más importante de toda la historia de Chile. Al respecto, Eltit desarrolla la idea de que Camila Vallejo supo administrar su propia belleza en favor del posicionamiento del movimiento estudiantil en los medios y en el inconsciente colectivo.

En esa misma línea, y reflexionando sobre la cuestión de género en el liderazgo de la dirigente, Helga María Lell (2012) señala que lo que resultaba más extraño para los medios era que Camila Vallejo no se hubiera masculinizado y cuidara de su apariencia, al mismo tiempo que era capaz de convocar a las masas y de oponerse a las autoridades de gobierno. De esta forma, los medios de comunicación mostraron muchas veces su perplejidad ante la condición de belleza de Camila Vallejo, como si esto fuese "un plus extraño de observar en una líder" (LELL, 2012, p. 178). 
Por su parte, Carolina Jara y Catalina Ruiz (2014) afirman que los medios de comunicación como Las Últimas Noticias colaboraron en posicionar a Camila Vallejo como una heroína combativa, pero también como una mujer atractiva y deseable, además de perfecta e ideal. Aunque, por otro lado, buscaban que estas características físicas dominaran el discurso periodístico.

Como era una de las posibilidades esperadas, Camila Vallejo siguió una carrera política, buscando visibilizar las demandas estudiantiles en espacios de poder institucionalizados. En el 2013, Camila Vallejo fue elegida diputada del Partido Comunista con un $43,66 \%$ de los votos, para el periodo 2014-2018. Posteriormente, en el 2017, fue nuevamente elegida como diputada para el periodo legislativo $2018-2022$, con un $13,7 \%$ de las votaciones.

\section{La metodología del Análisis Crítico del Discurso}

Para la fase metodológica de esta investigación se utilizó como herramienta el Análisis Crítico del Discurso (conocido también como ACD), un enfoque de estudio del discurso de carácter cualitativo que forma parte de los Estudios Críticos del Discurso. El ACD tiene como principal objetivo denunciar los abusos de poder en los discursos, con el fin de evidenciar las desigualdades sociales y demostrar la discriminación y los prejuicios contra ciertos grupos sociales.

Se reconoce al ACD por estudiar casos concretos de situaciones comunicativas. Una de las particularidades del ACD es que éste entiende el discurso como una forma de práctica social, es decir, que reconoce la relación dialéctica (que no es siempre bidireccional) entre un discurso y las situaciones y estructuras sociales que lo contienen. Y que, si bien son reproductoras de las desigualdades sociales, también son capaces de transformar la sociedad (Norman FAIRCLOUGH; Ruth WODAK, 2000). EI ACD considera los efectos ideológicos en las prácticas discursivas, que no siempre suelen resultar evidentes para las personas, en este sentido "EI ACD se propone logar que estos aspectos opacos del discurso se vuelvan más transparentes" (FAIRCLOUGH; WODAK, 2000, p. 368).

Teun Van Dijk, señala que el ACD "está referido principalmente a descubrir el modo en que el abuso del poder social, el dominio y la desigualdad son practicados, reproducidos, y de vez en cuando combatidos, por los textos y el habla en el contexto social y político" (VAN DIJK, 1999, p. 23). Entenderemos aquí el ACD como un acercamiento inter o multidisciplinar a los discursos y las comunicaciones, que estudia todos los niveles y dimensiones del discurso, sin necesariamente limitarse a sus componentes verbales. EI ACD se ocupa también de las dimensiones cognitivas, emocionales, sociales, políticas, culturales e históricas (VAN DIJK, 1999).

Considerando lo anterior, el ACD no corresponde a una metodología específica de análisis de discurso. En el ACD es lícito utilizar todas las metodologías y herramientas de los estudios discursivos y de las humanidades y ciencias sociales. Aquí es importante entender que el ACD es por sobre todo una perspectiva crítica, que intenta desarrollar y sostener un compromiso global de solidaridad con los grupos oprimidos. Esto supone un gran reto, especialmente en las sociedades democráticas, puesto que en los regímenes totalitarios es mucho más evidente quiénes son los dominadores. En cambio, en democracia, el poder se ve más diluido, teniendo en cuenta que son diferentes grupos los que compiten, y que no necesariamente existe un solo grupo que controle todo el discurso público. Por otro lado, el poder muchas veces no se ejerce de manera abusiva, sino a través de leyes y normas, o de acciones que racionalizamos como naturales. De aquí que la desigualdad se manifieste de maneras diferentes en las sociedades contemporáneas.

EI ACD aparece en la investigación académica como una reacción frente a los paradigmas formales, que se denominan asociales o acríticos. En el ACD, en cambio, los analistas toman partido por los grupos oprimidos de manera explícita, esperando contribuir a la disminución de las brechas sociales, y generando conocimiento y opiniones que contribuyan a producir cambios de carácter político y social (VAN DIJK, 1999). Frente a las diversas críticas que han surgido desde las disciplinas formales, que han tachado el ACD de acientífico y politizado, el ACD rechaza tales planteamientos, sosteniendo que toda investigación es política, incluso si no toma partido expresamente frente a una problemática social.

Al respecto, Fairclough y Wodak (2000) sostienen que el ACD se enmarca en una conciencia crítica general sobre el papel que juegan las prácticas lingüísticas y comunicativas dentro de nuestra vida social. Este rasgo crítico sería, primeramente, característico de la vida social contemporánea y, secundariamente, sería una tarea académica.

\section{Análisis a Las Últimas Noticias}

Como se mencionó, esta investigación aborda desde el Análisis Crítico del Discurso las entregas noticiosas del diario sensacionalista chileno de cobertura nacional Las últimas Noticias. Según cifras de Valida, el organismo encargado de la validación y lectura de los medios impresos en Chile, durante el primer semestre del año 2011, Las Últimas Noticias fue el segundo 
diario de mayor circulación. Durante el segundo semestre se dio la misma dinámica. En términos de lectoría neta (papel y digital), fue el primer diario más leído en Chile el año 2011.

Las Últimas Noticias fue fundado en el año 1902 y pertenece al consorcio de medios de comunicación El Mercurio S.A.P, parte del duopolio de la prensa en Chile y que concentra la mayor parte de los diarios nacionales y regionales en nuestro país. Durante la dictadura presidida por Augusto Pinochet, los diarios de El Mercurio S.A.P. ocultaron crímenes de lesa humanidad a través de la cobertura noticiosa e incluso, según el informe del Comité Church (1975) del Congreso de Estados Unidos, Agustín Edwards, propietario de El Mercurio, recibió ayuda económica de la Agencia Central de Inteligencia (CIA) para desestabilizar al régimen socialista de Salvador Allende.

En los años 90, el diario Las Últimas Noticias estuvo en peligro, debido a una vertiginosa baja de circulación. En 1996, Agustín Edwards decidió poner a cargo de este periódico a su hijo, y el medio dio un giro radical. La nueva dirección comenzó a experimentar con el periodismo amarillista, o también llamado sensacionalista, y Las Últimas Noticias comenzó así su característico estilo de farándula, publicando todo lo relacionado a los rostros de la televisión local (jet sef) y deportistas, centrándose en su vida personal, especialmente en la amorosa. La estrategia dio resultado y se convirtió en un rentable negocio para el grupo El Mercurio.

Considerando la importancia de este medio de comunicación escrito fue que se decidió estudiar la forma en la que había representado a Camila Vallejo. Para el análisis se seleccionaron los discursos periodísticos del género informativo (portadas, notas periodísticas y entrevistas) del diario Las Últimas Noticias en los que apareciera mencionada Camila Vallejo, durante los años 2010 y 2011 . En específico, se revisó el periodo durante el cual Camila Vallejo se desempeñó como presidenta de la Fech, del 11 de noviembre del 2010 al 19 de diciembre del 2011.

Esta selección arrojó un total de 99 discursos pertinentes para analizar en profundidad, tres de ellos correspondientes al año 2010 y 96 al año 201 1. La búsqueda y selección de discursos se realizó a partir de los contenidos que el diario Las Últimas Noticias presentaba a consulta de manera abierta en su página en internet.

\section{Resultados del análisis}

Respecto a la distribución de los 99 textos noticiosos seleccionados de Las Últimas Noticias entre noviembre del 2010 y diciembre del 2011, podemos observar que el mes que arroja mayores resultados es agosto del 2011 , con un total de 25 discursos. Le siguen septiembre con 16 discursos, octubre con 13 y julio con 12 (Ver Gráfico 1).

Gráfico 1. Distribución por mes de los discursos analizados. Fuente: Elaboración propia. \#PraTodoMundoVer El Gráfico 1 presenta la distribución lineal de los discursos analizados desde el mes de noviembre del año 2010 hasta el mes de diciembre del año 2011. Se puede ver que la línea llega a su mayor altura en agosto de 2011 con 25 discursos noticiosos.

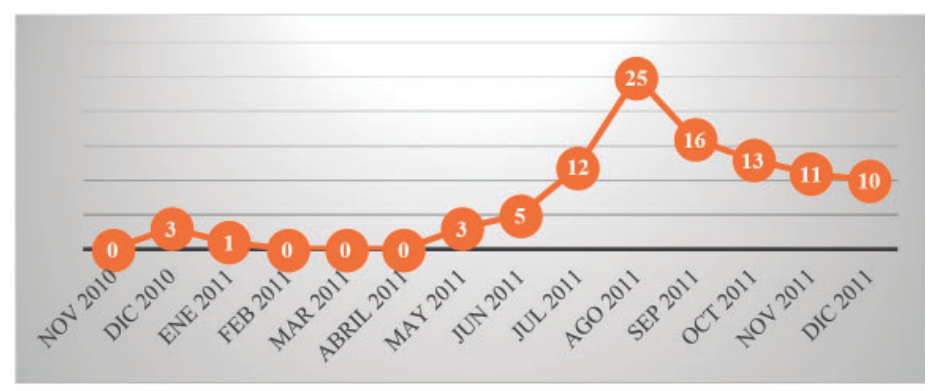

Durante el mes de noviembre del 2010 no se menciona a Camila Vallejo en las publicaciones, pero en el mes de diciembre de ese mismo año se la da a conocer a los lectores de Las Últimas Noticias. Su presencia resulta marginal, y desaparece entre febrero del 2011 y abril del 2011. En mayo del 2011 vuelve a aparecer y en julio del 2011 toma fuerza.

En términos de secciones, es posible señalar que un $84 \%$ de los discursos informativos pertenece a la sección Políica, 7\% pertenece a la sección El Día, 7\% a Revistas, $1 \%$ a la sección Sociedad y $1 \%$ a la sección Deportes. En la categoría Revistas, se encontraron seis artículos publicados en la revista Reportajes y un artículo en la revista M (Ver Gráfico 2).

Gráfico 2. Secciones del diario donde aparecen discursos sobre Camila Vallejo. Fuente: Elaboración propia. \#PraTodoMundoVer El Gráfico 2 presenta en forma circular la distribución por secciones del diario en las que aparecen más discursos sobre Camila Vallejo. La sección dominante es "Política", con un $84 \%$ de las informaciones. Le siguen "El Día" y "Revistas", con un $7 \%$ cada una.

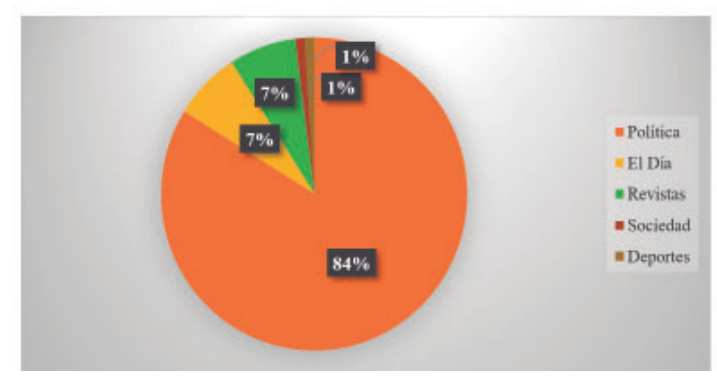


La mayoría de los textos noticiosos son breves, considerando que 41 de ellos corresponden a una extensión de 1 y 2 párrafos, y le siguen 17 textos con una extensión de 3 y 4 párrafos. A medida que la extensión en cantidad de párrafos va aumentando, disminuye la cantidad de noticias publicadas (Ver Gráfico 3).

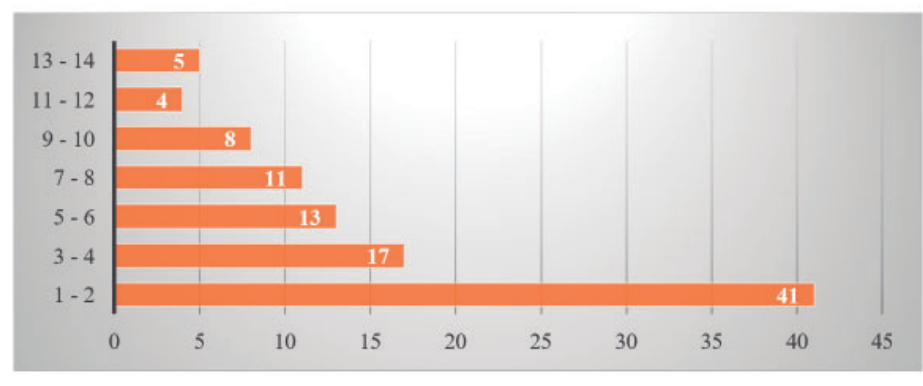

Gráfico 3. Extensión en párrafos de los discursos analizados.

Fuente: Elaboración propia.

\#PraTodoMundoVer El Gráfico 3 representa en barras la extensión de los discursos analizados, y los clasifica según la cantidad de párrafos. Se aprecia que a medida que los párrafos aumentan, la cantidad de noticias encontradas disminuye.

Considerando el enfoque de género de esta investigación, se quiso reflexionar también sobre la autoría tanto de los textos como de las imágenes de los discursos. Sobre el sexo de los periodistas que publicaron estos textos, un $43 \%$ corresponde a autores hombres y un $17 \%$ corresponde a autoras mujeres, en tanto que un $40 \%$ de los textos no tenía información respecto a la autoría.

En lo que se refiere al sexo de los autores de las fotografías, un 55\% son hombres y un $9 \%$ son mujeres. En el resto de las imágenes que complementan los textos noticiosos no se puede identificar el sexo del autor (36\%), puesto que pertenecen a agencias de noticias, son capturas de televisión o simplemente no se indica la autoría.

Un aspecto interesante para analizar fueron las actitudes dominantes en las fotografías de Camila Vallejo. Se logró llegar a dos actitudes presentes: Camila Vallejo Angelical y Camila Vallejo Seria. Podemos distinguir que la actitud principal es la Angelical, que muestra a Camila Vallejo dulce e inocente, presente en un $79 \%$ de las fotografías. Por su parte, con la actitud Seriedad, que exhibe a Camila Vallejo severa y grave, se presentan un $20 \%$ del total.

Respecto a Camila Vallejo como persona, encontramos diferentes representaciones de ella, que se traducen en una serie de estereotipos de género en los que los periodistas de Las Últimas Noticias la hacen encajar forzosamente. Se van construyendo así una serie de roles para Camila Vallejo, entre los que se puede mencionar los siguientes:

a) La mujer objeto: Se destaca a Camila Vallejo principalmente por su belleza física, la que es evidente, pues cumple con los cánones de la belleza occidental. Se señala que "Su belleza tipo Ornella Muti deslumbró" (13/12/2010), que la "Presidenta de la Fech se lamenta por ser tan linda" (23/01/201 1, ver Imagen 1), se la menciona como "la belleza comunista" (31/05/2011) o se sostiene que "los varones de La Moneda, léase galanes de prensa y funcionarios de Palacio, quedaron cautivados con la muchacha" (12/08/2011). Por esto, podemos decir que Camila Presidenta de la Vallejo no pertenece al estereotipo de mujer chilena promedio y por eso se Fech se lamenta por ser tan linda distingue del resto, especialmente en la política universitaria.

Imagen 1. Presidenta de la Fech se lamenta por ser tan linda. Fuente: Las Últimas Noticias, 23/01/201 1.

\#PraTodoMundoVer La Imagen 1 presenta una noticia de un párrafo que se titula "Presidenta de la Fech se lamenta por ser tan linda". La noticia va acompañada por una fotografía horizontal de Camila Vallejo en plano americano. Camila Vallejo se ve muy sonriente, mira directamente a la cámara, con el cabello suelto y largo, en una pose relajada. Viste una camiseta roja con botones y un pantalón azul. Tiene ambas manos en los bolsillos de su pantalón.

Tanto en los textos como en las fotografías se hace énfasis en el hermoso rostro de Camila Vallejo, sobre todo en sus llamativos ojos claros, y también en su aro en la nariz, símbolo de su rebeldía. Así lo podemos apreciar cuando se señala que Camila Vallejo es "una chica guapa, de hermoso rostro y alucinantes ojos azules" (23/01/2010), o que "otros derechamente no daban crédito que una mujer de tez blanca y ojos azules fuera de izquierda" (14/08/2011).

También se destaca su figura, que, además, se aprecia claramente en las fotografías como un cuerpo joven y deseable. Así se entiende cuando se sostiene que Camila Vallejo es "Sexy, tierna y pokemona" (25/08/2011), o que "Tras el momento erótico-revolucionario, se fue en taxi" (26/08/201 1). Camila Vallejo es reducida a ser un objeto de deseo sexual para los hombres, quienes exigen que su cuerpo sirva a sus intereses, que esperan, por ejemplo, que 
realice un baile sensual en medio de un discurso político, como en "Camila Vallejo no quiso mover la colita" (22/08/201 1, Imagen 2), o también cuando se señala que "El sol, aliado de ellos, además dejaba ver a una Camila no tan abrigada, vestida con una polera roja que destacaba su delgada figura, un ajustado jeans y su infaltable banano" (22/08/2011).

Imagen 2. Camila Vallejo no quiso mover la colita.

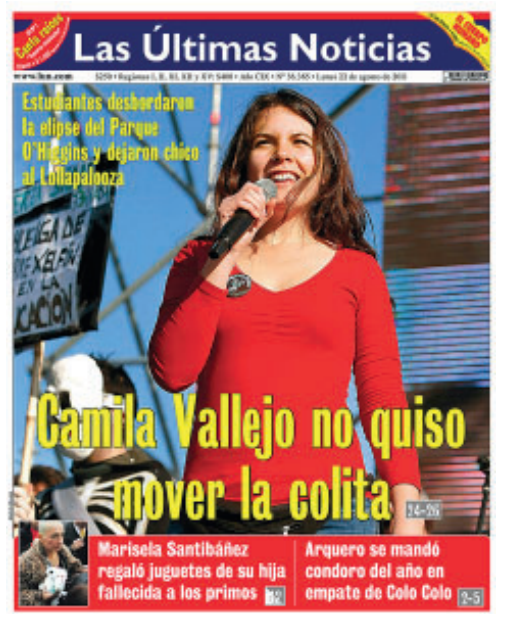

Fuente: Las Últimas Noticias, 22/08/2011.

\#PraTodoMundoVer La Imagen 2 presenta una portada del diario Las Últimas Noticias. El título es "Camila Vallejo no quiso mover la colita" se señala además que los "Estudiantes desbordaron la elipse del Parque O'Higgins y dejaron chico al Lollapalooza". La fotografía, que ocupa gran parte de la portada, es vertical y muestra a Camila Vallejo en plano americano, hablando con un micrófono. Camila Vallejo aparece sonriente, con el cabello suelto. Ella viste una camiseta de manga larga de color rojo y un pantalón azul de mezclilla y además lleva un banano (riñonera) negro. Detrás de ella podemos ver a una persona disfrazada de esqueleto, sosteniendo un cartel, y también hay una estructura metálica y una pantalla gigante.

Por otro lado, también se nos da a entender que Camila Vallejo es una mujer fatal, pues se sabe bella y utiliza la potestad que le da esa belleza para su beneficio personal. En este caso, para conseguir ser presidenta de la Fech y convocar a la sociedad chilena en torno a las demandas y preocupaciones del movimiento estudiantil. Es decir, ella utiliza el sexo para atraer el poder político, y su belleza sería el anzuelo para el público. Por ejemplo, cundo nos encontramos con la siguiente pregunta "Usted cumple con rasgos valorados socialmente, por no decir que es bonita. ¿El voto hormonal fue parte del debate?" (06/12/2010) o frente a la afirmación de que en el Congreso "el comentario del día era la belleza de la joven y esbelta representante comunista de la Universidad de Chile" $(07 / 12 / 2010)$ o que el "Vicepresidente boliviano también babea por Camila" (14/08/2011, Imagen 3). En este sentido, Camila Vallejo solamente importa en cuanto a ícono de belleza, y no se les da profundidad a sus ideas.
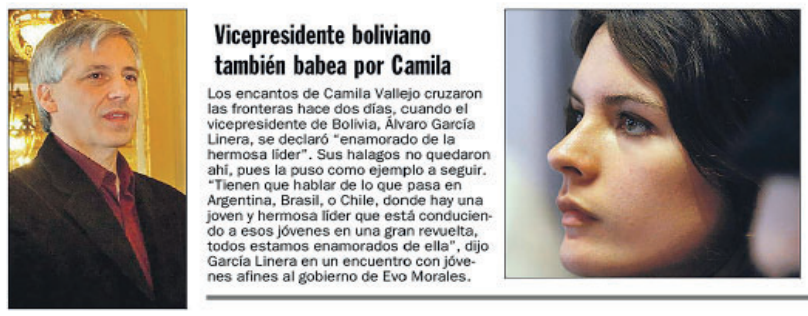

Imagen 3. Vicepresidente boliviano también babea por Camila.

Fuente: Las Últimas Noticias, 14/08/2011.

\#PraTodoMundoVer La Imagen 3 presenta una noticia de un párrafo que se titula "Vicepresidente boliviano también babea por Camila". El texto va acompañado por dos fotografías, una de Álvaro García Linera, vicepresidente de Bolivia, y la otra de Camila Vallejo. Álvaro García Linera se ve en un plano medio corto vertical, con el cabello muy canoso, vistiendo una camisa color burdeos y una chaqueta oscura. Camila Vallejo se muestra de perfil, en un primerísimo primer plano.

b) La comunista: Camila Vallejo se exhibe siempre como una líder comunista. Por ejemplo, se la nombra como "Camila, la líder rutilante que rejuveneció al Partido Comunista en su Congreso" (13/12/2010), "la joven dirigente de las Juventudes Comunistas" (06/06/2011), "La líder comunista" (25/08/2011), "La militante comunista Camila Vallejo" (15/11/2011) o también como "la joven comunista" (11/12/2011). Se destaca su militancia políica en las Juventudes Comunistas, relacionándola ideológicamente a Cuba y Venezuela. Camila Vallejo se presenta también como atea, combativa y aguerrida. Inclusive, se da a entender que Camila Vallejo está siendo manejada desde el Partido Comunista, y se infiere que todos sus logros son méritos del comunismo. Ella sería una herramienta del Partido Comunista para controlar y atraer a las masas.

c) La rockstar: Camila Vallejo es presentada como si fuera una personalidad del espectáculo. Se menciona que "La muchacha parecía rockstar" (22/08/2011) o que "Ios dirigentes fueron acogidos como rockstars" (15/10/2011). Tiene fanáticos, fans, que la acosan constantemente para pedirle fotografías y saludos. Esto se manifiesta en frases como "Guardia pretoriana la protegió de toqueteos, cámaras y escolares fanáticos" (10/08/2011) o bien en "Camila Vallejo mostró un hombro y sus fans se le fueron encima" (26/08/201 1, Imagen 4). 


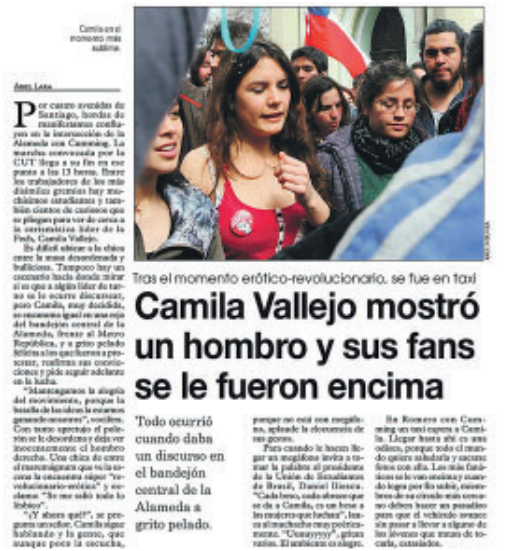

Imagen 4. Camila Vallejo mostró un hombro y sus fans se le fueron encima.

Fuente: Las Últimas Noticias, 26/08/2011.

\#PraTodoMundoVer La Imagen 4 presenta una noticia de seis párrafos, cuyo título es "Camila Vallejo mostró un hombro y sus fans se le fueron encima". El epígrafe señala "Tras el momento eróticorevolucionario, se fue en taxi", en tanto que en la bajada se puede leer "Todo ocurrió cuando daba un discurso en el bandejón central de la Alameda a grito pelado". La noticia va acompañada de una fotografía de orientación horizontal, en la que aparece Camila Vallejo caminando entre algunas y algunos jóvenes. Camila Vallejo se muestra con los ojos cerrados, en un plano medio corto. Ella viste un cárdigan negro y una camiseta de tirantes de color rojo. Lleva el hombro derecho descubierto y se le ve parte de la ropa interior. El pie de foto señala "Camila Vallejo en el momento más sublime".

Todos quieren ver a Camila Vallejo, todos quieren conocerla. Es muy querida y demandada por la gente. Es "ondera", siempre sale bien en las fotografías y es la líder que está de moda. Se muestra a Camila Vallejo como si fuera parte de la farándula nacional, se destaca que ella es "Más de pasarela que de barricada" (04/10/2011).

d) La muchacha: Por otro lado, Camila Vallejo es tratada como una joven, una muchacha, una chica, e incluso como una niña, y no como una mujer. Al respecto, nos encontramos con los siguientes ejemplos: "esta muchacha de 22 años" (23/01/2011), "Esta chica quiere saber la verdad del gas lacrimógeno" (08/05/201 1), "Ios argumentos de la muchacha" (06/06/201 1) o "la muchacha de los ojos verdes" (18/09/2011). Al parecer, para Las Últimas Noticias, Camila Vallejo aún no se gana el derecho de ser tratada como una adulta madura y completa.

e) La enamorada: La prensa en general, y Las Últimas Noticias en particular, tienen mucho interés en conocer detalles de la vida privada de Camila Vallejo, como por ejemplo cuando se señala que "Cubanos encontraron al amor ideal de Camila Vallejo" (11/09/2011) o "lo que muchos admiradores nunca quisieron escuchar: la dirigenta de la Fech está feliz, enamorada y lleva tres años pololeando" (18/09/2011). Se muestra a Camila Vallejo enamorada, y, cómo no, de un militante comunista y además cubano, el estudiante de medicina Julio Sarmiento. Un romance revolucionario ideal, como se puede revisar en "El hombre más envidiado de la marcha" (23/09/2011, Imagen 5) y en "Julio es estudiante de medicina de la Chile, nació en Cuba, pero se vino a vivir a Santiago el 2002 y milita en el Partido Comunista, al igual que Camila" (23/09/201 1), o también cuando se señala que "Camila Vallejo fue a "Tolerancia cero" con su más fiel hincha: su pololo" (14/11/2011).

Imagen 5. El hombre más envidiado de la marcha. Fuente: Las Últimas Noticias, 23/09/2011. \#PraTodoMundoVer La Imagen 5 presenta una portada del diario Las Últimas Noticias. El título de la portada es "El hombre más envidiado de la marcha" y además señala que "Julio Sarmiento no se despegó de Camila Vallejo en la masiva movilización de ayer". En la fotografía vertical, que ocupa casi la totalidad de la portada, se puede ver a Julio Sarmiento abrazando a Camila Vallejo, en medio de varias personas en una calle. Julio Sarmiento es un hombre joven y alto, que viste una camisa a cuadros y mira seriamente hacia la cámara. Camila Vallejo se ve muy pequeña y parece asustada. Lleva su cabello suelto y viste una camiseta color negro y un collar.

f) La seria: Camila Vallejo es presentada como una joven muy seria, que muy pocas veces ríe, con pocos amigos y poca vida social, como se puede leer en "la siempre seria Camila Vallejo" (06/11/2011) o en "mirada entre seria y

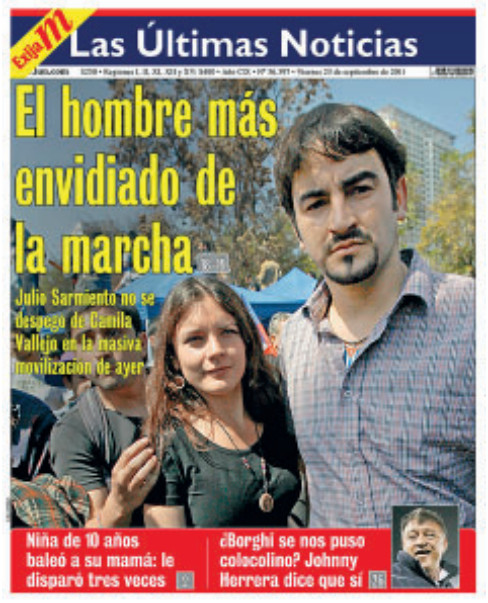
furibunda" (08/12/2011). Se expone a Camila Vallejo como una persona muy desconfiada, negativa y parca. Incluso se muestra que es violenta, odiosa y agresiva. Ella es malhumorada e irritable, y no acepta críticas.

g) La víctima: Se muestra a Camila Vallejo muchas veces como una víctima, como una mujer débil, que debe ser cuidada y protegida por los hombres, ya que ella sola no puede cuidar de sí misma. Lo anterior lo podemos ver en frases como "Guardaespaldas la cuida de gases y frescos" (26/06/2011), "Camila Vallejo, más cuidada que cartón ganador del Loto" (10/08/2011, Imagen 6), "Policías cuidan a Camila" (24/08/2011) o "Cinco hombres llegaron cuidando a Camila Vallejo" (25/08/2011). Se señala que Camila Vallejo ha sido amenazada y está constantemente en peligro. 


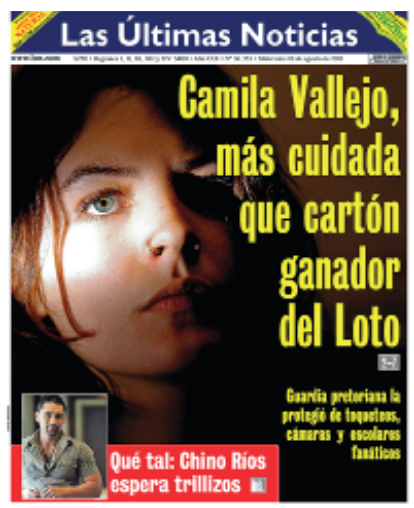

Imagen 6. Camila Vallejo, más cuidada que cartón ganador del Loto.

Fuente: Las Últimas Noticias, 10/08/2011.

\#PraTodoMundoVer La Imagen 6 presenta una portada del diario Las Últimas Noticias. En el título se señala "Camila Vallejo, más cuidada que cartón ganador del Loto" y se manifiesta que "Guardia pretoriana la protegió de toqueteos, cámaras y escolares fanáticos". La fotografía, que ocupa casi toda la portada, muestra a Camila Vallejo en un primerísimo primer plano. Hay mucha sombra y solamente se ve su ojo derecho bien iluminado. Camila Vallejo está muy seria. Se destaca el verde de su ojo y el piercing en su nariz.

h) La crítica: Camila Vallejo se presenta como crítica y contraria al gobierno de Sebastián Piñera, como una figura negativa en el conflicto estudiantil, intransigente, firme en su posición y que no quiere llegar a acuerdos con el Ejecutivo. Es posible observar esta postura en los siguientes textos " $Y$ en eso estaba Camila al anochecer, frente a él, tratando de doblarle la mano" (04/08/201 1), "desde donde aleonó a los dirigentes estudiantiles de todo el país (...) a seguir protestando aunque fuera sin permiso" (05/08/201 1) y especialmente en "Camila desafía a Piñera a un "cara a cara" en La Moneda" (28/08/2011). Se da a entender que ella no valora todos los esfuerzos que está haciendo el Gobierno. Se culpa a Camila Vallejo de internacionalizar el conflicto estudiantil chileno y de prolongarlo.

i) La endemoniada: Mención especial recibe la calificación de Cristián Labbé, por ese entonces alcalde de la comuna de Providencia, quien calificó a Camila Vallejo de endemoniada, como se puede revisar en "Labbé cree que Camila Vallejo está "endemoniada"' (21/08/2011, Imagen 7). El poder de Camila Vallejo sobre las masas es tal, que para la derecha chilena se ha convertido en la encarnación de mal, el demonio, la mujer-monstruo, que atrae y después devora.

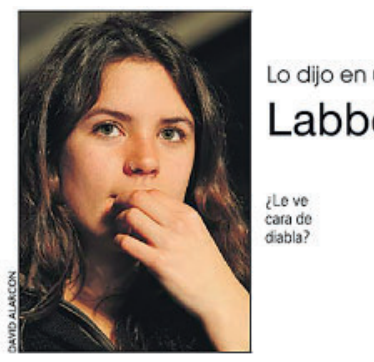

alijo en una entrevista radial. En la noche, la líder atribuyó los dichos a "nostalgia de la dictadura"
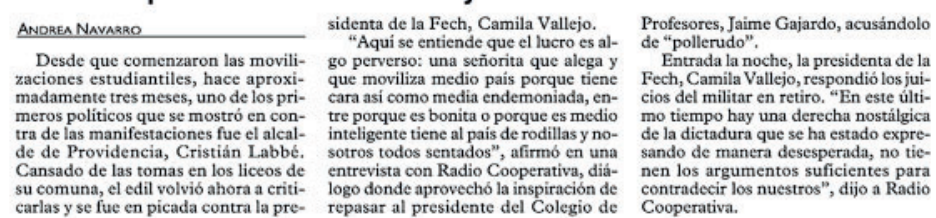

Imagen 7. Labbé cree que Camila Vallejo está "endemoniada".

Fuente: Las Últimas Noticias, 21/08/2011.

\#PraTodoMundoVer La Imagen 7 presenta una noticia de tres párrafos, cuyo título es "Labbé cree que Camila Vallejo está "endemoniada"”. Por otro lado, en el epígrafe se destaca "Lo dijo en una entrevista radial. En la noche, la líder atribuyó los dichos a "nostalgia de la dictadura"". El texto va acompañado de una fotografía de orientación vertical, en donde se ve a Camila Vallejo en primer plano. Camila Vallejo lleva el cabello suelto y viste ropa oscura, y tiene su mano izquierda en la boca. El pie de foto señala "iLe ve cara de diabla?"

\section{Conclusiones}

Según el Análisis Crítico del Discurso realizado a las entregas noticiosas publicadas por Las Últimas Noticias sobre Camila Vallejo durante su periodo como presidenta de la Fech, es posible señalar que la dirigente estudiantil se vio afectada por un tratamiento negativo, que se tradujo en una triple discriminación: por ser mujer (discriminación sexual), por ser comunista (discriminación ideológica) y por su juventud (discriminación etaria). De esta forma, entonces, se puede afirmar con claridad que los discursos del diario Las Últimas Noticias colaboraron en la creación y consolidación de una discriminación negativa hacia Camila Vallejo.

Se pudo constatar que Camila Vallejo era destacada por su belleza, por la que incluso se la criticaba, lo que sabemos que no ocurrió con los hombres voceros de la Confech y líderes del movimiento estudiantil universitario, que fueron abordados desde otras aristas noticiosas, y de los cuales la prensa no se preocupó de qué tan bellos eran, el color de sus ojos, o con qué ropa iban vestidos durante tal o cual ocasión. De la mano con lo anterior, se puede reconocer que la imagen de Camila Vallejo fue utilizada por Las Últimas Noticias como un señuelo, apelando principalmente al interés del público lector masculino, que se sentía muy atraído por su belleza. 
De esta manera, nos encontramos con una serie de estereotipos que fueron estimulados por el diario Las Últimas Noticias para reforzar y reproducir la discriminación negativa hacia Camila Vallejo, en lo que respecta a su sexo, su edad y su ideología. Los estereotipos de género que arrojó este análisis son los siguientes: la mujer objeto, la comunista, la rockstar, la muchacha, la enamorada, la seria, la víctima, la crítica y la endemoniada.

Es importante destacar también que gran parte de los textos y las imágenes analizadas fueron realizados por hombres, lo que nos permite señalar que este tipo de cobertura noticiosa tiene un sello sexista.

Respecto a la importancia de este tipo de estudios, es posible señalar que cada día se hacen más necesarios, considerando que, a pesar del techo de cristal, hay mujeres que logran conseguir cargos de elección popular, y sabemos que estas mujeres que se desenvuelven en la escena política están enfrentadas constantemente a críticas y descalificaciones, tanto de sus contrincantes, como de los medios de comunicación y de los propios ciudadanos y ciudadanas.

Es indiscutible, a partir de esta investigación, que se hace una diferencia de trato al hablar de las mujeres en los medios de comunicación, en este caso específico, en el discurso del diario Las Últimas Noticias sobre Camila Vallejo durante los años 2010 y 2011 . Corresponde preguntarnos si Camila Vallejo hubiera tenido tanta cobertura si no fuera considerada bella por los fotógrafos, periodistas y editores. Incluso las propias periodistas mujeres, al realizar el tratamiento noticioso sobre Camila Vallejo, caían en estereotipos de género, reduciéndola a un objeto sexual, sin reconocerla como sujeto político.

Desde allí se apela a la ética y a la responsabilidad de los periodistas como constructores de realidades, puesto que los medios de comunicación son uno de los mayores transmisores de estereotipos de lo que debería y no debería ser una mujer. Ellos promueven las imágenes culturales de lo que estamos posibilitadas a lograr y van así impulsando la discriminación. En vez de construir ejemplos de liderazgo femenino, destacando las habilidades y destrezas de las mujeres, siguen menospreciando sus logros.

Por otro lado, se ha hablado mucho sobre el movimiento estudiantil del 2011 como un hito en las movilizaciones sociales y de protesta en Chile. Pero uno de los aspectos fundamentales a destacar es que fue una mujer extremadamente joven la que, con su personalidad, carisma y conocimiento político, logró atraer la atención de la ciudadanía, de los medios de comunicación y de los líderes, tanto del gobierno como de la oposición. En este sentido, es posible afirmar que se generó una simbiosis entre las nobles demandas de los estudiantes movilizados y el encanto de Camila Vallejo, que este movimiento social estudiantil entendió como un valor agregado para convocar simpatizantes y movilizarlos.

\section{Referencias}

BONAVITTA, Paola; DE GARAY, Jimena. "De estereotipos, violencia y sexismo: la construcción de las mujeres en los medios mexicanos y argentinos". Anagramas Rumbos y sentidos de la comunicación, Medellín, v. 9, n. 18, p. 15-29. 2011. Disponible en https://revistas.udem.edu.co/ index.php/anagramas/article/view/472. Consultado el 10/08/2019.

DI BENNARDO, Filippo Giuseppe. La insurrección de Lilith: Breve recorrido histórico hasta la formulación de los arquetipos de mujer en la cultura judía/judío-cristiana y en la primera genealogía de la mitología griega. Sevilla: ArCiBel, 2009.

DORFMAN, Ariel; MATTELART, Armand. Para leer al Pato Donald: Comunicación de masa y colonialismo. Buenos Aires: Siglo XXI, 2002.

ELTIT, Diamela. "Camila Vallejo: Misión Cumplida". Revista Debate Feminista, Ciudad de México, v. 46, p. 189-198, octubre. 2012. Disponible en https://debatefeminista.cieg.unam.mx/df ojs/ index.php/debate feminista/article/view/935. Consultado el 10/08/2019.

FAIRCLOUGH, Norman; WODAK, Ruth. "Análisis crítico del discurso". In: VAN DIJK, Teun et al. EI discurso como interacción social: Estudios del discurso: introducción multidisciplinaria, Volumen 2. Barcelona: Gedisa, 2000. p. 367-404.

FIGES, Eva. Actitudes patriarcales: Las mujeres en la sociedad. Madrid: Alianza Editorial, 1972.

GARCÉS, Mario. El despertar de la sociedad: Los movimientos sociales en América Latina y Chile. Santiago: LOM, 2012.

GUTIÉRREZ, Fabiola; MAUREIRA Mónica. Medios no sexistas: Guía de definiciones y prácticas periodísticas [En línea]. 2018. Disponible en http://oge.cl/wp-content/uploads/2018/05/Guia-NoDiscriminacion.pdf. Consultado el 10/08/2019. 
ISRAEL, Estrella. Comunicación y periodismo en una sociedad global: Comunicar la diferencia. Sevilla: Trillas Eduforma, 2006.

JARA, Carolina; RUIZ, Catalina. La representación social de una líder estudiantil: el enfoque de un diario popular, Camila Vallejos en Las Últimas Noticias. 2014. Licenciatura (Licenciatura en Comunicación Social). Universidad Católica de Valparaíso, Valparaíso, Chile.

LELL, Helga María. "Discurso y liderazgo político: género y juventud en la legitimación de Camila Vallejo". Revista Internacional de Ciencias Sociales y Humanidades SOCIOTAM, Ciudad Victoria, v. XII, n. 1, p. 169-193. 2012. Disponible en https://www.redalyc.org/articulo.oa?id=65429254009. Consultado el 10/08/2019.

MOI, Toril. Teoría literaria feminista. Madrid: Cátedra, 1999.

NASH, Mary. Mujeres en el mundo: Historia, retos y movimiento. Madrid: Alianza Editorial, 2012.

ROMERO, Pamela. "Análisis crítico de la representación informativa de Camila Vallejo y el Movimiento Estudiantil chileno 2011 en el diario Las Últimas Noticias". Revista Estudios sobre el Mensaje Periodístico, Madrid, v. 19, n. 2, p. 871888. 2013. Disponible en https://revistas.ucm.es/ index.php/ESMP/article/view/43477. Consultado el 10/08/2019.

SALAS, Valentina. Sexismo, lenguaje y prensa: Caso Venezuela. Caracas: Fondo de Desarrollo de las Naciones Unidas para la Mujer, 2005.

SÁNCHEZ, Beatriz. Poderosas. Santiago de Chile: Aguilar, 2014.

SAU, Victoria. Manifiesto para la liberación de la mujer. Barcelona: Bruguera, 1975.

SILVA ECHETO, Víctor. "Las representaciones y los simulacros: La mujer en el cine y los medios de comunicación". In: ALIAGA, José Luis et al. Las Mujeres, los Saberes y la Cultura. Sevilla: ArCiBel, 2003. p. 63-67.

SUÁREZ, J. Carlos. Estereotipos de mujer en los medios de comunicación [En línea]. 2017. Disponible en https://www.nodo50.org/mujeresred/IMG/pdf/estereotipos.pdf. Consultado el 10/08/2019.

VALCÁRCEL, Amelia. Sexo y filosofía: Sobre "mujer" y "poder". Madrid: Horas y HORAS la editorial, 2013.

VALLEJO, Camila. Podemos cambiar el mundo. Santiago de Chile: Ocean Sur, 2012.

VAN DIJK, Teun. "El análisis crítico del discurso". Revista Anthropos, Barcelona, n. 186, p. 23-36, septiembre-octubre. 1999. Disponible en http://www. discursos.org/oldarticles/El\%20an\%E 1 lisis\%20 cr\%EDtico\%20del\%20discurso.pdf. Consultado el 10/08/2019.

WACC. ¿Quién Figura en las noticias? El Proyecto de Monitoreo Global de Medios GMMP 2015 [En línea]. 2015. Disponible en https://whomakesthenews.org/wp-content/uploads/who-makesthe-news/lmported/reports_2015/global/gmmp_global report_es.pdf. Consultado el 10/08/2019.

Pamela Soledad Romero Lizama (pamela.romero@ucn.cl) es Periodista y Licenciada en Comunicación Social. Magíster en Comunicación y Doctora en Ciencias Humanas con mención en Discurso y Cultura por la Universidad Austral de Chile. Ha trabajado como investigadora en proyectos vinculados al pluralismo en la prensa, análisis crítico del discurso, interculturalidad, imagen, género y movimientos sociales. Actualmente se desempeña como académica de la Escuela de Periodismo de la Universidad Católica del Norte. 


\section{COMO CITAR ESTE ARTÍCULO, DE ACUERDO CON LAS NORMAS DE LA REVISTA}

ROMERO LIZAMA, Pamela Soledad. "Estereotipos de género sobre Camila Vallejo en un diario sensacionalista chileno: el caso de Las Últimas Noticias". Revista Estudos Feministas, Florianópolis, v. 29, n. 2, e67774, 2021.

\section{CONTRIBUCIÓN DE AUTORÍA}

No se aplica.

\section{FINANCIACIÓN}

No se aplica.

\section{CONSENTIMIENTO DE USO DE IMAGEN}

No se aplica.

\section{APROBACIÓN DE COMITÉ DE ÉTICA EN INVESTIGACIÓN}

No se aplica.

\section{CONFLICTO DE INTERESES}

No se aplica.

\section{LICENCIA DE USO}

Este artículo tiene la licencia Creative Commons License CC-BY 4.0 International. Con esta licencia puedes compartir, adaptar, crear para cualquier finalidad, siempre y cuando cedas la autoría de la obra.

\section{HISTORIAL}

Recibido el 26/09/2019

Presentado nuevamente el 30/11/2020

Aprobado el 18/12/2020 